\title{
Evaluation of User Experience in Translator Applications (Banjar-Indonesian and Indonesian- Banjar) Based on Mobile Augmented Reality Technology using the UX Honeycomb Method
}

\author{
Aulia Akhrian Syahidi \\ Interactive Media, Game, and Mobile Technologies \\ Research Group, \\ Augmented Reality and Virtual Reality Laboratory, \\ Politeknik Negeri Banjarmasin \\ Banjarmasin, Indonesia \\ aakhriansyahidi@poliban.ac.id
}

\author{
Herman Tolle \\ Media, Game, and Mobile Technologies Research Group, \\ Faculty of Computer Science, \\ Universitas Brawijaya \\ Malang, Indonesia \\ emang@ub.ac.id
}

\begin{abstract}
The translator application from Banjar Language to Indonesian is called BandoAR and vice versa from Indonesian to Banjar Language which is called NdoBAR. Both applications utilize Mobile Augmented Reality technology with the Optical Character Recognition (OCR) Method for word recognition in the detected image. This application is recommended and used to help tourists visiting the city of Banjarmasin to be able to understand the language used by local people as a means of communication and for the general public who want to know the peculiarities of the Banjar language itself. The purpose of this study was to evaluate the user experience of the BandoAR and NdoBAR applications. The method used is UX Honeycomb, which has seven aspects to assess the user experience of an application. A total of 50 respondents were presented to assess the two applications. The results showed that the BandoAR application had an average UX Honeycomb value of 4.91 with a Very Strongly Agree predicate and for the NdoBAR application, an average value of UX Honeycomb was 4.89 with a Very Strongly Agree predicate. Both applications have fulfilled aspects of the user experience.
\end{abstract}

Keywords-mobile augmented reality; optical character recognition; translator app; user experience; ux honeycomb method.

\section{INTRODUCTION}

In today's era, the boundaries between the digital and physical worlds are increasingly difficult to distinguish. Augmented Reality Technology or AR Technology is rapidly entering a new phase that allows its users to get a context-rich User Experience (UX) within the AR application. The context in question is a context that combines sensors, computing, the Internet of Things (IoT), and Artificial Intelligence. AR technology will bring significant transformation to many areas of the economy in terms of productivity, competitiveness, as well as providing new and innovative services to its clients.

Applications of AR technology-based applications include in the entertainment sector (such as Games: Pokemon Go!), the health sector (such as medical training in magnetic resonance imaging using AR Headsets), the education sector (such as the use of AR for practice in vocational learning), aviation (such as F-35 helmet which can help pilots to see a 360-degree view around the plane), broadcasting and television (such as flood, earthquake, and even tsunami simulation), Language field (such as AR-based translator in real-time ), and other fields that can take advantage of AR technology in an application.

In Norman's view, it is not enough to just create an application that can function properly and can be used, but an application is also required to present a pleasant impression for its users, including an effective and best possible UX [1]. This is no exception in designing $\mathrm{AR}$ applications, which must also provide a better UX from the interactions offered.

Several factors that make this UX influential and important in an application are: (1) Based on research from HubSpot in [2] which states that smartphone users are reported to tend to leave web pages, if the display is not optimized properly. This concerns if the application or usage is not compatible with their smartphone. You can imagine if more than half of smartphone users leave, then your business can certainly run in place or even crash; (2) Research conducted by Imaginovation in [2] states that if the content you have is not interesting, then $79 \%$ of users will leave your website; (3) The research institute Mindtouch also released the importance of UX which was conveyed in [2] by giving an example of an incident experienced by ESPN.com which is a well-known and very large sports website, which has experienced a $35 \%$ increase in revenue after redesigning their homepage ; (4) Adobe also researched the importance of UX, which was presented in [2] stating that from the research results it was found that users will leave the application when the application user interface takes too long to load.

In essence, the application you have is a major asset that must be managed as well as possible. If you don't have a satisfactory service, loading is very slow, then the customer will leave. For that, the development of this UX requires a fantastic cost. The word UX in the Google search engine is also trending. UX is very important to attract more customers. 
Seeing how important the role of UX is, its influence should of course be given great attention. This user experience has a huge impact on customer satisfaction, your brand, and the shopping experience.

Based on this urgency, this research focuses on assessing and evaluating the user experience of two translator applications named BandoAR and NdoBAR using the UX Honeycomb Method.

\section{THEORITICAL FRAMEWORK}

\section{A. Mobile Augmented Reality}

Augmented Reality (AR) is an amalgamation of real and virtual worlds that can run interactively in real-time and are served with 2D and or 3D object views [3]. AR technology can provide virtual object overlays into the real environment [4].

Meanwhile, according to [5] AR is a merger between the digital world and the real-world in real-time, AR technology uses the real-world environment at that time and then adds new information with the help of computers, webcams, and special glasses such as Google Glass. AR is a combination of digital objects in 2D and 3D with the real-world. According to [6] the term Mobile Augmented Reality refers to an AR application that can be installed and only focuses on the mobile device/smartphone when AR is used. The general way AR works on smartphone devices can be seen in Figure 1.

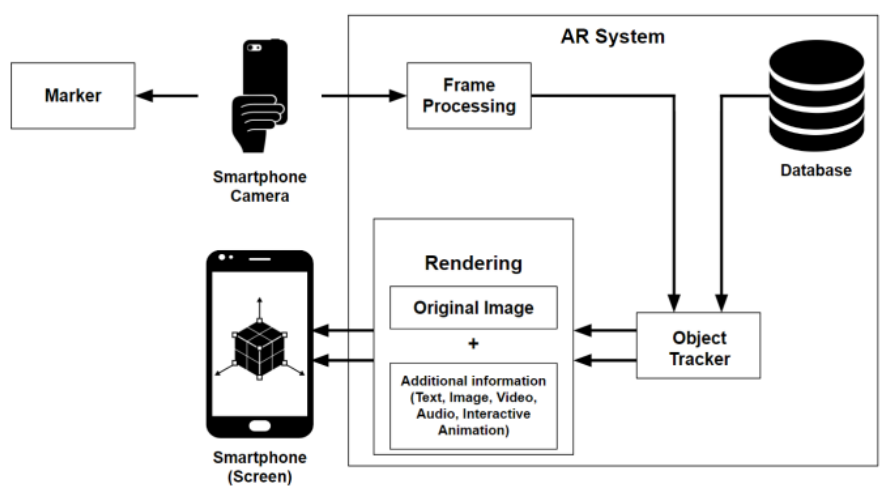

Fig. 1. AR system works

Based on Figure 1, the workflow of the AR system on a smartphone, namely the AR application will access the smartphone device camera, then the AR system will detect the marker via the camera, then it will match the detection pattern through the database, if detected according to the pattern, it will display a virtual object on the smartphone screen.

The tracking technique in AR consists of two methods, namely Marker-Based Tracking, and Markerless Tracking. Marker-Based Tracking is a special marker that is made like a barcode or black frame [5]. Meanwhile, according to [7] states that Marker-Based Tracking is a method that uses markers, namely in the form of black and white illustrations in the form of squares or image illustrations with certain colors and shapes. This method requires several things in its processing, such as a PC or smartphone equipped with cameras and sensors that support AR, AR applications, and markers.
The Markerless Tracking method is a natural marker that is directly related to the object [5]. Markerless Tracking is a method that does not require a marker to display virtual objects. The virtual object is projected by utilizing a part of the surrounding environment as a detection target. Markerless Tracking is usually used for face tracking, 3D object tracking, motion tracking, and also GPS-Based Tracking [7].

\section{B. Optical Character Recognition}

Optical Character Recognition (OCR) is the process of converting a letter image into ASCII characters that can be recognized by a computer. The image of the letters in question can be in the form of a document scan, a print-screen result of a web page, a photo, etc. [8]. Furthermore, according to [9] OCR can assist in digitizing handwritten manuscripts.

The OCR system continues to be developed today so that it can produce better accuracy even in situations such as characters that are difficult to recognize. The application of OCR itself allows the computer to carry out further processing, for example, translation into a foreign language, search, automatic reading system for blind people, data input, character recognition such as license plates, CAPTCHA testing, or other text problems. The results of the OCR can be saved directly in ASCII form, but in certain cases, it is necessary to save the layout. What is meant by layout is the position of paragraphs, margins, and others, so that they are exactly the same as the processed image.

\section{User Experience Evaluation in Mobile Application}

According to the International Organization for Standardization (ISO) in his research [10] stated that UX is defined as the result of the user's mindset and response based on the results of using a system, product, or service.

UX can describe how the user experience in accessing an application to solve various needs. These experiences include how users explore the features that exist in an application more optimally. UX can include the interaction between the user and the content in the application. To create a satisfactory UX, of course, requires special skills and strategies in the form of thinking, innovation, and application based on experience. UX is subjective and can change over time. UX design is the process of creating applications that are fun to interact with and provide a meaningful experience.

The benefits of UX include providing convenience for users, increasing user trust, the level of user trust is strongly influenced by the ability (performance) shown by the application and all service features provided to help solve user problems, and good UX is believed to be able to increase the number of users [1].

Tips in designing a good UX include a balanced visual design, asking other people's opinions (it would be better to directly ask the opinion of prospective application users), choose simple and clear navigation, and choose the font type that suits the application version.

Regarding UX in mobile-based applications, it includes the subjective experience that users have with mobile-based applications. This includes both good and bad experiences, as well as emotions. UX can go beyond a purely graphical 
representation of the UI and is also concerned with designing the experiences users have before, during, and after using the mobile-based application.

An investigation of UX, especially on mobile-based applications, has been carried out by [11] who stated that five categories of influencing UX that arise through the results of interactions with applications include user factors, social factors, cultural factors, the context of use, and product-related factors. Then based on the categories, special attributes are also mentioned which include motivation, user emotions, norms, social involvement, time, place, usability, and size.

In designing UX for mobile-based applications, there are several principles such as (1) Size, i.e. content must be able to adjust to the size of the smartphone, it is recommended that only one column be used to load content where users can scroll down to view further content; (2) Screen orientation which requires making mobile-based applications that have two different orientations, namely landscape/horizontal and portrait/vertical positions, because users tend to position smartphones with portrait/vertical orientations more than landscape/horizontal. Furthermore, the designer must arrange the main features or clickable icons so that users can reach everything with one thumb because users tend to use one thumb more in interacting with content on mobile-based applications; (3) Navigation and input, which is like providing a touch-layer-based keyboard that makes it easy for users to input data (it should be noted that the keyboard offered depends on what the user has to input). Furthermore, make sure the button that will be touched by the user is large enough to make it easier for fingers to tap, besides touching, other gestures must be considered in the interaction, namely scrolling, sliding, dragging down, and tapping (long, short, or double-tap). ; (4) Environment, namely designing applications that are easy to use anywhere and anytime and can be used outdoors, paying attention to coloring with high contrast so that when there is an effect from sunlight, the application can be seen clearly. Furthermore, also pay attention to the input that is concise and simple, and not complicated. (5) Split-screen, namely paying attention to designs that can be accessed with a split-screen display; (6) Symbols, namely paying attention to the symbols or icons used by adjusting the prevalence and standardization, avoiding using unusual symbols or icons, because they will confuse users; (7) Seamless design, namely paying attention to a seamless design.

In research [12] stated that UX in mobile-based AR applications is very important to increase interaction for its users, especially AR enriched with interesting magical elements. Furthermore, [6] stated that UX in the AR system is an interaction that is as important as the interface, users tend to prefer applications that are easy and comfortable to use.

\section{Banjar Language}

Banjar language is a language designated for the Banjar tribe in South Kalimantan Province as the mother tongue [13]. The Banjar language is one of the languages in Kalimantan which has a fairly wide area of use, which includes the areas of Central Kalimantan, East Kalimantan, and South Kalimantan as the area of native speakers [14]. Research from [14] seeks to explore the origins of the Banjar language and visualize it on a chart which can be seen in Figure 2.

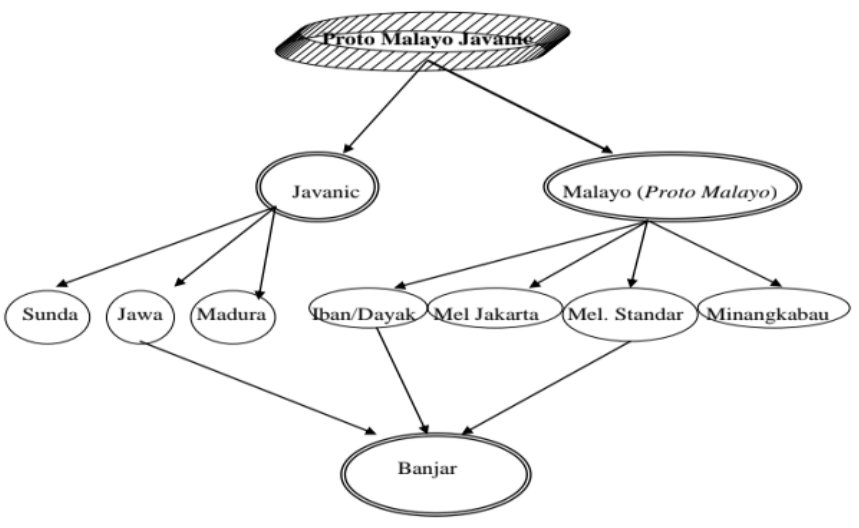

Fig. 2. Chart of the origins of the Banjar Language

Based on Figure 2, the genetically Banjar language is part of Proto Malayo Javanic, which is the result of the interaction of three languages (Malay, Javanese, and Dayak) which is then added to the original vocabulary as a result of the interactive triangle.

The Banjar language has two dialects, namely the Banjar Dialect Hulu and the Banjar Dialect Kuala. There are some phonemes and vocabularies of the Banjar Dialect Hulu which have similarities with Indonesian although their position is different [15]. The resemblance, similarities, and also differences between the Banjar Dialect Hulu and Indonesian are presented in Table I.

TABLE I. EXAMPLES OF RESEMBLANCE, SIMILARITY, AND DIFFERENCES OF BANJAR DIALECT HULU LANGUAGE AND INDONESIAN LANGUAGE

\begin{tabular}{|c|c|}
\hline \multicolumn{2}{|c|}{ Resemblance } \\
\hline Banjar Dialect Hulu Language & Indonesian Language \\
\hline Lambat & Lambat \\
\hline Kayu & Kayu \\
\hline Malam & Makan \\
\hline Makan & Indonesian Language \\
\hline \multicolumn{2}{|c|}{ Similarity } \\
\hline Banjar Dialect Hulu Language & Hari \\
\hline Bari & Lubang \\
\hline Ari & Meja \\
\hline Luwang & Indonesian Language \\
\hline Mija & Cantik \\
\hline Banjar Dialect Hulu Language & Mampu \\
\hline Bungas & Arah \\
\hline Kawa & Luas \\
\hline Ampah
\end{tabular}

Based on Table 1, the Banjar Dialect Hulu and Indonesian have similarities, namely recognizing vowels (a), (i), and (u). The similarity is seen in terms of disclosure that leads to certain phonemes. There are also differences between the two and they are numerous.

\section{RESEARCH METHODOLOGY}

The stages carried out in this study can be seen in Figure 3. 


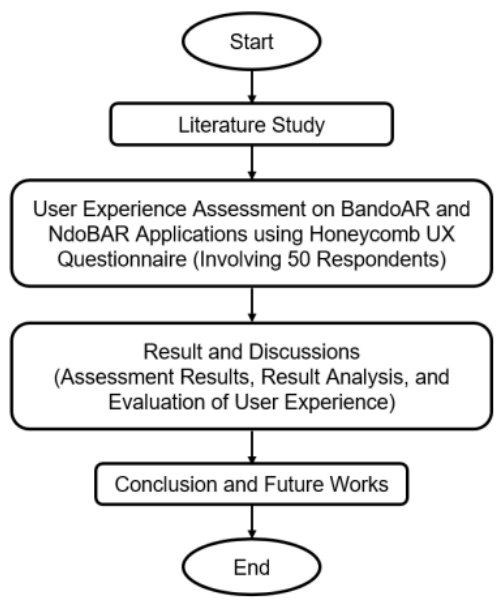

Fig. 3. Research methodology

Based on Figure 3, the research starts from the literature study stage, which is looking for similar research that applies the UX Honecomb Method in evaluating UX in mobile-based applications and knowing how the results and assessment techniques are. Next is the UX assessment stage on the BandoAR and NdoBAR applications by presenting 50 respondents to participate in using a questionnaire using the UX Honeycomb Method. The UX Honeycomb method is used because it is suitable for UX evaluation on mobile-based applications. Then the results and discussion stage, which describes the results of the UX assessment, analyze the results and evaluates the assessments that have been carried out. The last stage is to conclude the research and provide recommendations for further work.

The UX Honeycomb method is a user experience assessment method specifically for mobile-based applications that was initiated by Peter Morville. In UX Honeycomb, there are seven aspects to assess and go beyond the usability aspect, these seven aspects are in the form of a hexagon that resembles a honeycomb adopted from [16] and can be seen in Figure 4.

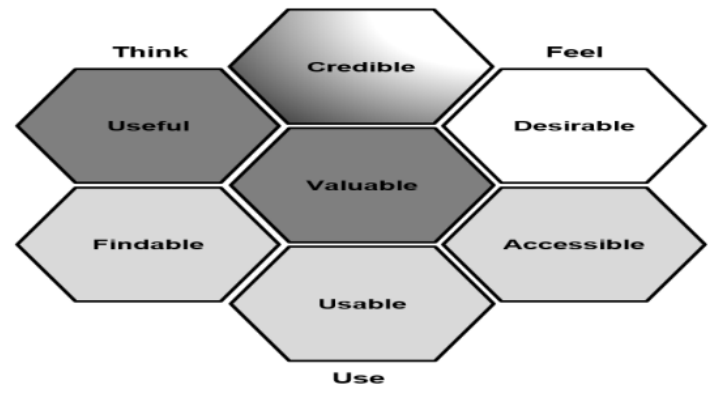

Fig. 4. Aspects in UX Honeycomb

Based on Figure 4, it is a Honeycomb UX diagram optimized by drawing useful relationships between its different parts to convey how users can use the application, express their thoughts on using the application, and express how they feel when using the application.

The description of the aspects in UX Honeycomb are as follows:
1. Useful which shows that the application can solve the problems that the user has (example: there is a flight ticket application, the application can help users in ordering plane tickets quickly, effectively, and safely).

2. Usable which shows that the application is easy to use, no matter how good the user interface design is, if the ease of application aspect is ignored, it will make the user disappointed.

3. Desirable which relates to the consideration of pleasing user interface design, color combinations, and the use of appropriate fonts.

4. Findable which pays attention to the clarity of navigation and does not confuse users in interacting, not only that, the time element in the speed of accessing the features in the application is also considered in this aspect so that the application is more responsive.

5. Accessible, which requires applications to be accessed with various capabilities.

6. Credible which refers to the user's ability to trust the application made such as ethical application feasibility, durability, security, and accuracy.

7. Valuable is a combination of all aspects and relates to applications that can have value for its users.

The question items used to assess UX by adjusting the aspects of UX Honeycomb are presented in Table II.

TABLE II. QUESTION ITEMS ON THE UX HONEYCOMB QUESTIONNAIRE

\begin{tabular}{|c|c|c|}
\hline $\begin{array}{l}\text { Aspects of } \\
\text { UX } \\
\text { Honeycomb }\end{array}$ & Id & Question Items \\
\hline \multirow{2}{*}{ Useful } & UXH-01 & $\begin{array}{l}\text { Can the BandoAR/NdoBAR application } \\
\text { solve user problems? }\end{array}$ \\
\hline & UXH-02 & $\begin{array}{l}\text { Does the BandoAR/NdoBAR application } \\
\text { meet the user's needs? }\end{array}$ \\
\hline Usable & UXH-03 & $\begin{array}{l}\text { Does the BandoAR/NdoBAR application } \\
\text { provide ease of use? }\end{array}$ \\
\hline \multirow[b]{2}{*}{ Desirable } & UXH-04 & Is the BandoAR/NdoBAR app fun to use? \\
\hline & UXH-05 & $\begin{array}{l}\text { Does the combination of color and type of } \\
\text { writing feel right? }\end{array}$ \\
\hline \multirow{3}{*}{ Findable } & UXH-06 & $\begin{array}{l}\text { Is the BandoAR/NdoBAR application } \\
\text { interaction clear (not confusing in use)? }\end{array}$ \\
\hline & UXH-07 & $\begin{array}{l}\text { Does the placement of buttons and navigation } \\
\text { in the BandoAR/NdoBAR application feel } \\
\text { right? }\end{array}$ \\
\hline & UXH-08 & $\begin{array}{l}\text { Does the BandoAR/NdoBAR application } \\
\text { have a good response time? }\end{array}$ \\
\hline Accessible & UXH-09 & $\begin{array}{l}\text { Does the BandoAR/NdoBAR application } \\
\text { have a good design and have more } \\
\text { capabilities? }\end{array}$ \\
\hline Credible & UXH-10 & $\begin{array}{l}\text { Can the BandoAR/NdoBAR application } \\
\text { provide confidence in the security of personal } \\
\text { data? }\end{array}$ \\
\hline Valuable & UXH-11 & $\begin{array}{l}\text { Can the BandoAR/NdoBAR application be of } \\
\text { value to you? }\end{array}$ \\
\hline
\end{tabular}

To get a score when respondents fill out the questionnaire, a Likert Scale is used which is adapted from the research [12] with a positive statement score consisting of 1 for Strongly Disagree, 2 for Disagree, 3 for Agree, 4 for Strongly Agree, and 5 for Very Strongly Agree. The results of the UX 
assessment are then calculated and obtained the average results of each application and an evaluation is carried out to recommend suggestions and decisions for further improvement.

\section{RESUlT AND DisCUSSIONS}

The BandoAR application is a mobile-based translator application from Banjare to Indonesian, using OCR Technology to process the conversion of letter images into ASCII characters that have been detected and AR Technology as a user interface area that can visualize the appearance of text from the detection results that have been translated [5].

BandoAR and NdoBAR applications were created and developed by the Politeknik Negeri Banjarmasin, Universitas Brawijaya, and Saga University teams. The user interface of the BandoAR application can be seen in Figure 5.

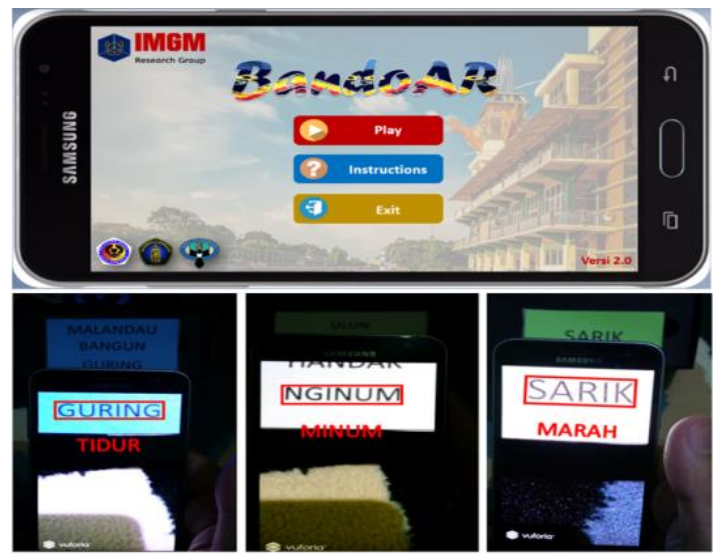

Fig. 5. BandoAR user interface

Based on Figure 5, BandoAR uses a Markerless Tracking Method (natural markers/independent of permanent/special markers). BandoAR application is constantly evolving to increase the number of words in the database and also improve the user interface and better UX.

The NdoBAR application is a mobile-based translator application from Indonesian to Banjarese. AR technology is also a user interface area that can visualize the appearance of text from the detection results that have been translated. The user interface of the BandoAR application can be seen in Figure 6.

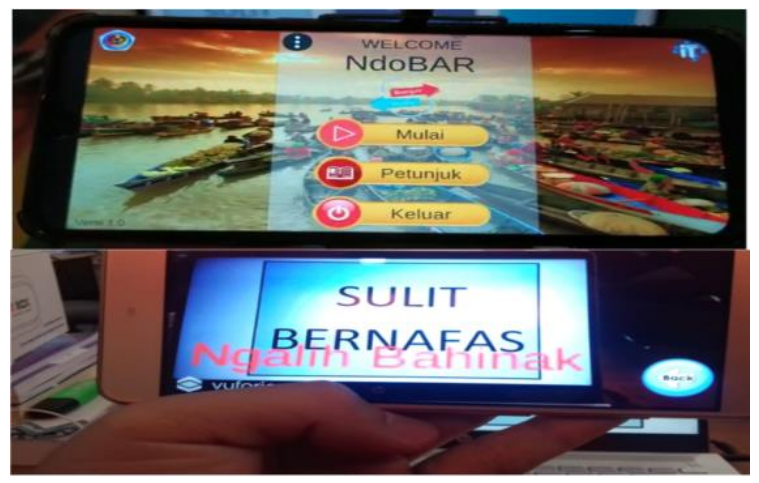

Fig. 6. NdoBAR user interface
The birth of these two applications is based on the problem of the sadness of local South Kalimantan culturalists about the erosion of the use of the Regional Language (Banjar Language) caused by the flow of technology and information which has an impact on the entry of foreign cultures. According to Suseno in [17], the Banjar language as a social language should receive attention and protection from the local government.

Furthermore, it is not only a problem, but also based on opportunities, because South Kalimantan is also a city with a promising tourist destination, local and foreign tourists often visit. However, sometimes tourists find it difficult to communicate with Banjar who use the Banjar Language, so these two applications can be recommended.

To be able to improve the performance of the two applications, a UX assessment has been carried out involving as many as 50 respondents from local tourists and several tourists from abroad. The results of the UX assessment of the BandoAR application are presented in Table III and the UX assessment of the NdoBAR application is presented in Table IV.

TABLE III. UX ASSESSMENT RESULTS ON BANDOAR

\begin{tabular}{|c|c|c|c|c|c|c|c|c|}
\hline $\begin{array}{c}\text { Aspects of } \\
\text { UX } \\
\text { Honeycomb }\end{array}$ & Id & $\mathbf{1}$ & $\mathbf{2}$ & $\mathbf{3}$ & $\mathbf{4}$ & $\mathbf{5}$ & $\begin{array}{c}\text { Answer } \\
\text { Results }\end{array}$ & Mean \\
\hline \multirow{2}{*}{ Useful } & UXH-01 & 0 & 0 & 0 & 0 & 50 & 250 & 5 \\
\cline { 2 - 10 } & UXH-02 & 0 & 0 & 0 & 0 & 50 & 250 & 5 \\
\hline Usable & UXH-03 & 0 & 0 & 0 & 2 & 48 & 248 & 4.96 \\
\hline \multirow{2}{*}{ Desirable } & UXH-04 & 0 & 0 & 0 & 20 & 30 & 230 & 4.6 \\
\cline { 2 - 9 } & UXH-05 & 0 & 0 & 0 & 20 & 30 & 230 & 4.6 \\
\hline \multirow{2}{*}{ Findable } & UXH-06 & 0 & 0 & 0 & 0 & 50 & 250 & 5 \\
\cline { 2 - 9 } & UXH-07 & 0 & 0 & 0 & 0 & 50 & 250 & 5 \\
\cline { 2 - 9 } & UXH-08 & 0 & 0 & 0 & 0 & 50 & 250 & 5 \\
\hline Accessible & UXH-09 & 0 & 0 & 0 & 0 & 50 & 250 & 5 \\
\hline Credible & UXH-10 & 0 & 0 & 0 & 0 & 50 & 250 & 5 \\
\hline Valuable & UXH-11 & 0 & 0 & 0 & 6 & 44 & 244 & 4.88 \\
\hline & \multicolumn{7}{|c|}{ Overall Average } \\
\hline
\end{tabular}

Based on Table III, the overall average value of the UX assessment on the BandoAR application is 4.91 with the Very Strongly Agree predicate which means that the BandoAR application has implemented aspects that exist in the UX Honeycomb, but needs further improvement.

The highest rating is spread on items with Id UXH-01 with an average value of 5 , where users feel that the BandoAR application can solve problems, namely as a translator medium and they also find it helpful. Then the item with Id UXH-02 with an average value of 5, where users feel that the BandoAR application has met their needs. Furthermore, the item with Id UXH-06 with an average value of 5, where users feel the clarity of the BandoAR application interaction. On items with Id UXH-07 with an average value of 5, where users feel that the placement of buttons and navigation is appropriate. For items with Id UXH-08 with an average value of 5, where users feel that the BandoAR application response time is very fast. Then for items with ID UXH-09 with an average value of 5, where users feel that the BandoAR application has a good design and provides more capabilities. Finally, for items on Id UXH-10 with an average value of 5 , where users feel that the 
BandoAR application can provide confidence in the security of personal data and the accuracy of the translator's results.

The lowest value on Id UXH-04 with an average value of 4.6, where the application needs to be improved to provide pleasure in using it. Then the same lowest value is also obtained for items with Id UXH-05, namely the need to increase the selection of color combinations and fonts when the detection results are displayed. Furthermore, what needs to be improved is the aspect of ease of use, so that the BandoAR application can be more valuable for its users.

TABLE IV. UX ASSESSMENT RESULTS ON NDOBAR

\begin{tabular}{|c|c|c|c|c|c|c|c|c|}
\hline $\begin{array}{c}\text { Aspects of } \\
\text { UX } \\
\text { Honeycomb }\end{array}$ & Id & $\mathbf{1}$ & $\mathbf{2}$ & $\mathbf{3}$ & $\mathbf{4}$ & $\mathbf{5}$ & $\begin{array}{c}\text { Answer } \\
\text { Results }\end{array}$ & Mean \\
\hline \multirow{2}{*}{ Useful } & UXH-01 & 0 & 0 & 0 & 0 & 50 & 250 & 5 \\
\cline { 2 - 9 } & UXH-02 & 0 & 0 & 0 & 0 & 50 & 250 & 5 \\
\hline Usable & UXH-03 & 0 & 0 & 0 & 4 & 46 & 246 & 4.92 \\
\hline \multirow{2}{*}{ Desirable } & UXH-04 & 0 & 0 & 0 & 20 & 30 & 230 & 4.6 \\
\cline { 2 - 9 } & UXH-05 & 0 & 0 & 0 & 30 & 20 & 220 & 4.4 \\
\hline \multirow{2}{*}{ Findable } & UXH-06 & 0 & 0 & 0 & 0 & 50 & 250 & 5 \\
\cline { 2 - 9 } & UXH-07 & 0 & 0 & 0 & 0 & 50 & 250 & 5 \\
\cline { 2 - 9 } & UXH-08 & 0 & 0 & 0 & 0 & 50 & 250 & 5 \\
\hline Accessible & UXH-09 & 0 & 0 & 0 & 0 & 50 & 250 & 5 \\
\hline Credible & UXH-10 & 0 & 0 & 0 & 0 & 50 & 250 & 5 \\
\hline Valuable & UXH-11 & 0 & 0 & 0 & 4 & 46 & 246 & 4.92 \\
\hline & \multicolumn{7}{|c|}{ Overall Average } \\
\hline
\end{tabular}

Based on Table IV, the overall average value of the UX assessment on the NdoBAR application is 4.89 with the predicate Very Strongly Agree, which means that the NdoBAR application has implemented aspects that exist in UX Honeycomb, but needs further improvement.

The highest rating is spread on items with ID UXH-01 with an average value of 5 , where users feel that the NdoBAR application can solve problems, namely as a translator medium and they also find it helpful. Then the item with ID UXH-02 with an average value of 5 , where users feel that the NdoBAR application has met their needs. Furthermore, the item with Id UXH-06 with an average value of 5, where users feel the clarity of the NdoBAR application interaction. On items with Id UXH-07 with an average value of 5, where users feel that the placement of buttons and navigation is appropriate. For items with ID UXH-08 with an average value of 5, where users feel that the response time of the NdoBAR application is very fast. Then for items with ID UXH-09 with an average value of 5 , where users feel that the NdoBAR application has a good design and provides more capabilities. Finally, for items on Id $\mathrm{UXH}-10$ with an average value of 5 , where users feel that the NdoBAR application can provide confidence in the security of personal data and the accuracy of the translator's results.

The lowest value is on Id UXH-05 with an average value of 4.4 , where it is necessary to improve the selection of color combinations and fonts when the detection results are displayed in the NdoBAR application. Furthermore, what needs to be improved is the aspect of ease of use, application design to be more pleasant when used, so that the NdoBAR application can be more valuable for its users.

\section{CONCLUSION AND FUTURE WORKS}

Based on the results of the UX assessment with the UX Honeycomb Method for the two translator applications, it is necessary to further improve several items in the UX Honeycomb aspect. These items include the selection of font color combinations when the detection results appear and also improvements to ease of use.

Future work will be to improve the UX of the two applications, assessing the user interface and usefulness of the two applications to society. Furthermore, it also improves performance and other intelligent capabilities related to media translators.

\section{ACKNOWLEDGMENT}

This research was fully supported by the team from the Interactive Media, Game, and Mobile Technologies (IMGM) Research Group and also the Augmented Reality and Virtual Reality (ARVR) Laboratory, Politeknik Negeri Banjarmasin.

\section{REFERENCES}

[1] G. Allanwood and P. B. Beare, "User Experience Design: Creating Design Users Really Love," London: Bedford Square, 2014.

[2] A. Nugroho, "Pentingnya User Experience untuk Menarik Banyak Konsumen," 2020, [Retrieved on: March 13, 2021, source: https://qwords.com/blog/user-experience-adalah/].

[3] R. T. Azuma, "A Survey of Augmented Reality," In Presence: Teleoperators and Virtual Environments, 1997, pp. 355-385.

[4] H. Kato and M. Billinghurst, "Marker Tracking and HMD Calibration for a Video-Based Augmented Reality Conferencing System," in Proceedings of the $2^{\text {nd }}$ IEEE and ACM International Workshop on Augmented Reality (IWAR), 1999, pp. 1-10.

[5] A. A. Syahidi, H. Tolle, A. A. Supianto, and K. Arai, "BandoAR: RealTime Text Based Detection System Using Augmented Reality for Media Translator Banjar Language to Indonesian with Smartphone," in Proceedings of the $5^{\text {th }}$ IEEE International Conference on Engineering Technologies and Applied Sciences (ICETAS), 2018, pp. 1-6.

[6] Subandi, A. A. Syahidi, Joniriadi, and A. Mohamed, "Mobile Augmented Reality Application with Multi-Interaction for Learning Solutions on the Topic of Computer Network Devices (Effectiveness, Interface, and Experience Design)," in Proceedings of the $3^{\text {rd }}$ International Conference on Vocational Education and Electrical Engineering (ICVEE), 2020, pp. 1-6.

[7] U. M. Arief, H. Wibawanto, and A. L. Nastiti, "Membuat Game Augmented Reality (AR) dengan Unity 3D," Yogyakarta: Andi Publisher, 2019.

[8] F. Mohammad, J. Anarase, M. Shingote, and P. Ghanwat, "Optical Character Recognition Implementation Using Pattern Matching," International Journal of Computer Science and Information Technologies, vol. 5, no. 2, 2014, pp. 2088-2090.

[9] J. Memon, M. Sami, R. A. Khan, and M. Uddin, "Handwritten Optical Character Recognition (OCR): A Comprehensive Systematic Literature Review (SLR)," IEEE Access, vol. 8, 2020, pp. 142642-142668.

[10] S. Irshad and D. R. A. Rambli, "Advances in Mobile Augmented Reality from User Experience Perspective: A Review of Studies," in Proceedings of the International Visual Informatics Conference SpringerLink, vol. 10645, 2017, pp. 466-477.

[11] X. Sun and A. May, "A Comparison of Field-Based and LabBased Experiments to Evaluate User Experience of Personalised Mobile Devices," Advances in Human-Computer Interaction, vol. 2013, no. 2, 2013, pp. 1-9.

[12] A. A. Syahidi, Subandi, and A. Mohamed, "AUTOC-AR: A Car Design and Specification as a Work Safety Guide Based on Augmented Reality Technology," Journal of Technological and Vocational Education, vol. 26, no. 1, 2020, pp. 1-8.

[13] A. A. Syahidi, A. A. Supianto, and H. Tolle, "Design and Implementation of Bekantan Educational Game (BEG) as a Banjar 
Language Learning Media," International Journal of Interactive Mobile Technologies (iJIM), vol. 13, no. 03, 2019, pp. 108-124.

[14] M. F. Yasin, "Asal-Usul Bahasa Banjar (Tinjauan Historis Komparatif)," Banjarmasin: ULM Repository, 2017.

[15] Tim Balai Bahasa Banjar, "Kamus Bahasa Banjar Dialek HuluIndonesia Edisi Pertama," Jakarta: Departemen Pendidikan Nasional Pusat Bahasa, 2008.

[16] E. Macpherson, "The UX Honeycomb: Seven Essential Considerations for Developers," 2019, [Retrieved on: March 13, 2021, source: https://medium.com/mytake/the-ux-honeycomb-seven-essentialconsiderations-for-developers-accc372a398c].

[17] E. Rizkiyana, "Penggunaan Bahasa Banjar Terkikis, Budayawan Kalsel Merasa Miris," 2020, [Retrieved on: March 13, 2021, source: https://www.sonora.id/read/422396209/penggunaan-bahasa-banjarterkikis-budayawan-kalsel-merasa-miris]. 